\title{
HEAVY ATOM ENHANCED ROOM-TEMPERATURE PHOSPHORIMETRY FOR ULTRATRACE DETERMINATION OF HARMANE
}

\author{
Flávia F. de Carvalho Marques, Flávia da Silva Figueiredo and Ricardo Queiroz Aucelio* \\ Departamento de Química, Pontifícia Universidade Católica do Rio de Janeiro, Rua Marquês de São Vicente, 225, 22253-900 \\ Rio de Janeiro - RJ, Brazil \\ Recebido em 19/9/06; aceito em 10/8/07; publicado na web em 19/12/07
}

\begin{abstract}
Harmane has been proposed for the treatment of epilepsy, AIDS and leshmaniosis. Its room-temperature phosphorescence was induced using either $\mathrm{AgNO}_{3}$ or $\mathrm{TlNO}_{3}$, enabling absolute limits of detection of 0.12 and $2.4 \mathrm{ng}$ respectively, with linear dynamic ranges extending up to $456 \mathrm{ng}\left(\mathrm{AgNO}_{3}\right)$ and $911 \mathrm{ng}\left(\mathrm{TlNO}_{3}\right)$. Relative standard deviations around $3 \%$ were observed for substrates containing $46 \mathrm{ng}$ of harmane. Such sensitivity and precision are needed because harmane intake must be strictly controlled to achieve proper therapeutic response. Interference studies were performed using thalidomide, reserpine and yohimbine. Recovery of $104 \pm 6 \%$ was achieved using solid surface room-temperature phosphorimetry. The result was comparable to the one obtained by micellar electrokinetic chromatography.
\end{abstract}

Keywords: room-temperature phosphorescence; harmane; selective heavy atom effect.

\section{INTRODUCTION}

Instead of a single disease, epilepsy has been defined as a cluster of neurological disorders that has been focus of several studies in order to better understanding it ${ }^{1}$. Recent studies have demonstrated that $\beta$-carboline alkaloids may have strong effect on the threshold for inducing of epileptic seizures. Harmane (1-methyl $\beta$-carboline) (Figure 1) has prevented electroshock induced seizures in a dependentway dose. Increasing intakes of harmane has decreased the frequency of convulsions from $66 \%$ (using $2.5 \mathrm{mg}$ of harmane per $\mathrm{kg}$ ) to $20 \%$ (10.0 mg of harmane per $\mathrm{kg}$ ). However, the same study showed that chemically induced seizures (by the use of pentylenetetrazol) are decreased with the low intake of harmane $(2.5 \mathrm{mg}$ per $\mathrm{kg}$ ) while aggravated with the high dose of the drug (10 mg per $\mathrm{kg}$ ). This study has demonstrated the potential of harmane as a drug for the treatment of epilepsy if the drug intake is strictly controlled ${ }^{2}$.<smiles>Cc1nccc2c1[nH]c1ccccc12</smiles>

Figure 1. Harmane (1-methyl $\beta$-carboline)

$\beta$-carbolines have also other biological activities, acting as antimicrobial and hypotensive. They also have hallucinogenic and antioxidative properties ${ }^{3,4}$. Although harmane has not yet been used as the active principle of any commercial medicine, studies have indicated that this substance has antileishmanial and anti-HIV activity ${ }^{5-7}$.

Harmane is the main $\beta$-carboline alkaloid that occurs naturally in plants such as Peganum harmala and in other plant species throughout the world ${ }^{8}$. It is also found as a product of pyrolysis of indoles and proteins and thus occurs in cigarette smoke, charcoal grilled meats and teas ${ }^{9-11}$. Harmane can also be endogenously

*e-mail:aucelior@puc-rio.br produced in human and animal tissue as a product of secondary metabolism ${ }^{12}$, however, most generally, the presence of harmane and other $\beta$-carbolines in human body is from exogenous sources ${ }^{13}$.

Luminescence of harmane has been studied at $77 \mathrm{~K}^{14-16}$, however, no information on room-temperature phosphorescence and no studies concerning the influence of heavy atoms as enhancers of the phosphorescence signal have been reported. Solid surface roomtemperature phosphorimetry (SSRTP) has been established as a selective analytical technique, allowing ultratrace determination of many organic substances of environmental, clinical and biological interest, in special for alkaloids ${ }^{17,18}$. Phosphorescence of analytes of interest can be selectively induced in the presence of potential interferents by the right choice of the experimental conditions, in special, the use of selective heavy atom enhancers and the adjustment of the $\mathrm{pH}$ of the analyte solution to be spotted on the substrate ${ }^{17}$. The presence of heavy atoms in the vicinity of a molecule may induce or enhance its phosphorescence due to the increasing of the spin-orbit coupling interaction. This phenomenon may affect singlet-triplet transitions and either radiative or non-radiative decay from the excited triplet state, therefore, an increase in phosphorescence quantum yield does not always occur, being the selective nature of the external heavy atom effect based on these different interactions between analytes and heavy atoms ${ }^{17}$. The control of the $\mathrm{pH}$ of the analyte solution is a very important factor since variations of the $\mathrm{pH}$ may produce derivatives with larger phosphorescence quantum yield. Moreover, charged species formed in the solution may present higher phosphorescence owing to the fact that ionized species have greater molecular rigidity when adsorbed on the cellulose substrate ${ }^{19}$.

SSRTP may enable selective determination of harmane in the presence of other concominat substances (for instance, zidovudine, thalidomide, reserpine and yohimbine) without the need for previous separations. This feature may impose great advantages in terms of labor and operational cost when compared to HPLC based methodologies ${ }^{20,21}$. Because of its potential clinical applications and the dose-dependent response, the development of a simple and sensitive analytical method for the quality control of harmane based drugs is desirable. In the present work, SSRTP is evaluated as a 
tool for the determination of harmane in simulated pharmaceutical tablets. The goal is to achieve selective conditions to allow determination of harmane in such samples without the need for previous separation of other components in the sample.

\section{EXPERIMENTAL}

\section{Instrumentation}

Phosphorescence was measured on an LS-55 Perkin-Elmer spectrofluorimeter (Perkin-Elmer, Norwalk, USA). This instrument was equipped with a pulsed xenon arc lamp as the excitation source, two 1200 groves/mm diffraction gratings and a R928 photomultiplier detector. Phosphorescence was acquired using $3 \mathrm{~ms}$ delay and $3 \mathrm{~ms}$ gate times. Such conditions eliminated second order scattering and fluorescence background from samples. Spectral bandpass was set to $10 \mathrm{~nm}$. An adapted front surface accessory (Perkin-Elmer) was used to place the cellulose substrates for the measurements. This apparatus was modified to enable nitrogen purging directly onto the sample during measurements. Micellar electrokinetic chromatography (MEKC) determination was made on a capillary electrophoresis system (Agilent, USA).

Photochemical treatment for paper background reduction were carried out in a laboratory made photochemical reactor loaded with six mercury sterilization lamps $(6 \mathrm{~W}$ each one with maximum emission wavelength of the lamps at $254 \mathrm{~nm}$ ) placed on the top of the reactor.

\section{Reagents}

Filter paper (Whatman No. 42) treated in the laboratory for reduction of background was employed as a sample substrate. Deionized water (resistivity of $18.2 \mathrm{M} \Omega \mathrm{cm}$ ) from a water ultra purifier master system 1000 (Gehaka, Brazil), was used to prepare all aqueous solutions. Nitrogen (99.996 \%) was from White Martins, Brazil and it was further purified passing it through an ammonium metavanadate solution and dried in a silica gel bed. All reagents were of analytical grade and they were employed without further purification. Methanol, acetonitrile, urea, mercury (II) chloride, potassium iodide, lead (II) nitrate, sodium nitrate, sodium dodecil sulfate (SDS), boric acid, acetic acid, phosphoric acid, hydrochloric acid and sodium hydroxide were purchased from Merck (Brazil). Harmane, reserpine and yohimbine were provided by Sigma (USA). Thallium (I) nitrate and cadmium nitrate were from Across (USA). Thalidomide and zidovudine were donated by Microbiológica, Brazil. A formulation containing thalidomide (Talidomida CEME ${ }^{\circledR}$, Brazil) was used to simulate a harmane-associated medicine.

\section{Procedures}

The procedure for paper substrate background reduction was adapted from the traditional one ${ }^{18}$ in order to decrease its overall time from 16 to $4 \mathrm{~h}$. The procedure consisted on submitting filter paper strips to a hot boiling washing step ( $2 \mathrm{~h}$ in a Sohxlet extractor). After dried under an infrared lamp and cut in circles of $18 \mathrm{~mm}$ of diameter, in order to fit in the solid substrate cell, these substrates were then treated with UV radiation $(2 \mathrm{~h})$ in a photochemical reactor. This procedure reduced background from cellulose down to $95 \%$.

Methanol was employed to prepare harmane stock solutions. Analyte standard solutions were prepared by sequential dilutions of the stock solution with methanol/water $25 / 75 \%$, v/v. The $\mathrm{pH}$ of the analyte solutions was adjusted by adding either strong base or acid aqueous solutions or by using Britton-Robinson buffer (0.04 mol L ${ }^{-1}$ ). Deionized water was used to prepare all heavy atom salts and SDS solutions. The concentration of these solutions for the initial studies were $\mathrm{KI}\left(1.0 \mathrm{~mol} \mathrm{~L}^{-1}\right) \mathrm{TINO}_{3}\left(0.5 \mathrm{~mol} \mathrm{~L}^{-1}\right), \mathrm{Pb}\left(\mathrm{NO}_{3}\right)_{2}$ $\left(0.5 \mathrm{~mol} \mathrm{~L}^{-1}\right), \mathrm{Cd}\left(\mathrm{NO}_{3}\right)_{2}\left(0.25 \mathrm{~mol} \mathrm{~L}^{-1}\right), \mathrm{Hg}_{2} \mathrm{Cl}_{2}\left(0.25 \mathrm{~mol} \mathrm{~L}^{-1}\right), \mathrm{AgNO}_{3}$ ( $\left.0.01 \mathrm{~mol} \mathrm{~L}^{-1}\right)$ and SDS $\left(0.07 \mathrm{~mol} \mathrm{~L}^{-1}\right)$.

Five $\mu \mathrm{L}$ of analyte standard solutions or sample solutions were deposited on the paper substrate, using an adjustable micropipette. When necessary, the substrates were previously spotted with $5 \mu \mathrm{L}$ of surfactant (SDS) followed by $5 \mu \mathrm{L}$ the heavy atom solution. Then, the substrates with samples and blanks were dried at room temperature in a vacuum desiccator for approximately $2 \mathrm{~h}$. The desiccator was covered with aluminum foil in order to avoid possible effects from the ambient light. Three minutes prior to and during the phosphorescence measurement, a dry nitrogen flow was passed over the substrate surface to minimize quenching effects from oxygen and air moisture.

Laboratory made tablets were prepared by mixing $60 \mathrm{mg}$ of harmane with a pulverized pharmaceutical tablet containing 100 $\mathrm{mg}$ of thalidomide. This mixing was performed in a mechanical shaker for $1 \mathrm{~h}$. Six weighted portions of the powder were then separated and washed with methanol to dissolve harmane. The solution was vacuum filtered and the filtered solution was then diluted in methanol/Britton-Robinson buffer ( $\mathrm{pH} 11.0$ ) 25/75\%, $\mathrm{v} / \mathrm{v}$, when $\mathrm{AgNO}_{3}$ was used as phosphorescence enhancer, or in methanol/water $25 / 75 \%$, v/v when the phosphorescence enhancer employed was $\mathrm{TlNO}_{3}$.

The following conditions were used for MEKC: uncoated silica capillary $(50 \mathrm{~cm}$ effective length and $56 \mu \mathrm{m}$ internal diameter); applied potential of $25 \mathrm{kV}$; temperature of $30^{\circ} \mathrm{C}$; injection made at $50 \mathrm{mbar}$ for $10 \mathrm{~s}$. The MECK buffer was freshly prepared and typically consisted of $20 \mathrm{mmol} \mathrm{L}^{-1}$ borate buffer ( $\mathrm{pH} 9.0$ ) containing SDS $\left(50 \mathrm{mmol} \mathrm{L}^{-1}\right)$, urea $\left(0.6 \mathrm{~mol} \mathrm{~L}^{-1}\right)$ and acetonitrile $15 \%$, in volume. The absorption of the analyte peak was detected at 254 $\mathrm{nm}$. This procedure was adapted from Cheng and Mitchelson ${ }^{22}$.

\section{RESULTS AND DISCUSSION}

\section{RTP characteristics of harmane}

Room-temperature phosphorescence (RTP) of harmane was studied in three different conditions using several heavy atom salts as potential signal enhancers. First, harmane $\left(4 \times 10^{-4} \mathrm{~mol} \mathrm{~L}^{-1}\right)$ solutions were prepared dissolving the analyte in methanol/water $(25 / 75 \% \mathrm{v} / \mathrm{v})$ before spotting it on the cellulose substrate. Alternatively, previous to the deposition on the substrate, harmane solutions were prepared in acid or in basic conditions using respectively methanol/0.2 $\mathrm{mol} \mathrm{L}^{-1} \mathrm{HCl}$ solution $(25 / 75 \% \mathrm{v} / \mathrm{v})$ or methanol/0.2 mol L-1 $\mathrm{NaOH}$ solution $(25 / 75 \% \mathrm{v} / \mathrm{v})$.

While no phosphorescence was observed in basic conditions, a small phosphorescence from harmane was observed either from the methanol/water solution with the maximum excitation and emission wavelength pair $\left(\lambda_{\text {exc }} / \lambda_{\text {em }}\right)$ at $250 / 495 \mathrm{~nm}$ or from acid conditions at $250 / 504 \mathrm{~nm}$.

The effect of six heavy atom salts on the RTP characteristics of harmane was studied. From neither basic solution $(\mathrm{NaOH} 0.2 \mathrm{~mol} \mathrm{~L}$ $\left.{ }^{1}\right)$ nor acid solution $\left(\mathrm{HCl} 0.2 \mathrm{~mol} \mathrm{~L}^{-1}\right)$, significant harmane phosphorescence was observed in the presence of $\mathrm{KI}, \mathrm{TINO}_{3}, \mathrm{AgNO}_{3}$, $\mathrm{Cd}\left(\mathrm{NO}_{3}\right)_{2}, \mathrm{Hg}_{2} \mathrm{Cl}_{2}$ and $\mathrm{Pb}\left(\mathrm{NO}_{3}\right)_{2}$. For harmane prepared in methanol/ water solution, very intense phosphorescence is observed when it was placed on paper substrates containing either $\mathrm{TINO}_{3}$ or $\mathrm{AgNO}_{3}$ with signal amplification of 34 and 164 times respectively when compared to the phosphorescence from harmane in the absence of these phosphorescence enhancers. The phosphorescence spectra under 
these conditions are shown in Figure 2. No relevant phosphorescence was observed in the presence of the other four heavy atom salts.

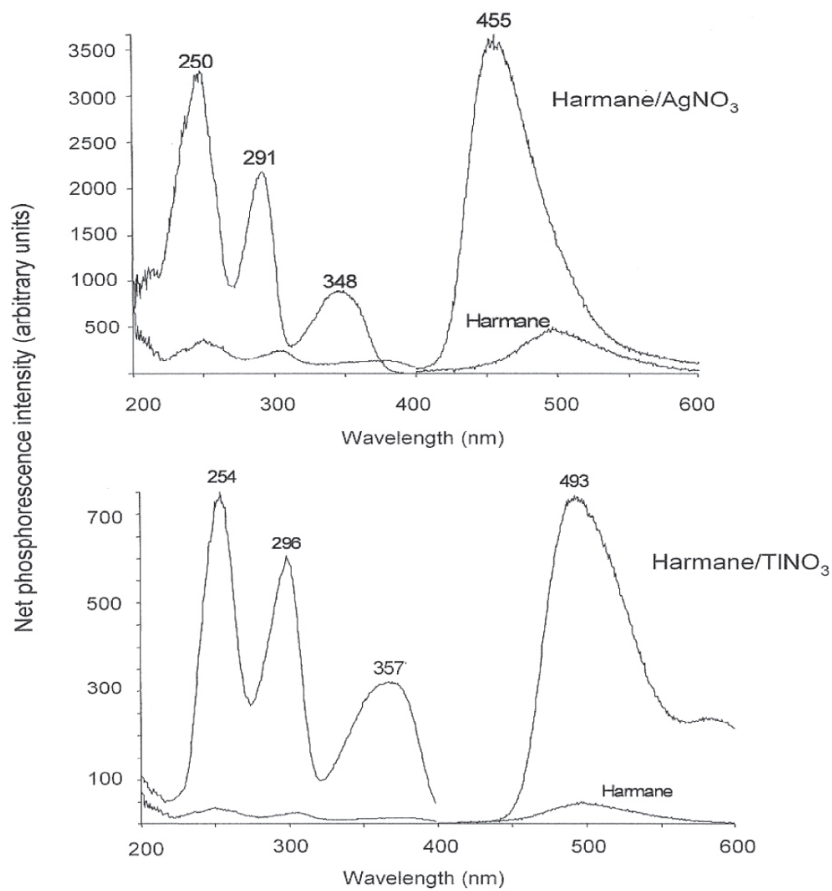

Figure 2. Room-temperature phosphorescence of harmane $\left(4 \times 10^{-4} \mathrm{~mol} \mathrm{~L}^{-1}\right)$

\section{Maximization of the harmane RTP signal}

Studies to maximize the RTP signal were performed using either $\mathrm{AgNO}_{3}$ or $\mathrm{TlNO}_{3}$ in the substrate. A more specific study to evaluate the influence of the $\mathrm{pH}$ (Britton-Robinson buffer with $\mathrm{pH}$ values between 2 and 12) of the analyte solution to be spotted on the substrate was also performed. In substrates containing $\mathrm{TINO}_{3}$, no significant variation of signal was observed between $\mathrm{pH} 2.0$ and $\mathrm{pH}$ 10.0. For solutions of higher $\mathrm{pH}$ values, a decreasing of signal was observed. Therefore, no Britton-Robinson buffer was used in the harmane solutions to be deposited on substrates containing $\mathrm{TlNO}_{3}$. For substrates containing $\mathrm{AgNO}_{3}$, the best signals were found from analyte solutions prepared at $\mathrm{pH} 11.0$ as illustrated in Figure 3.

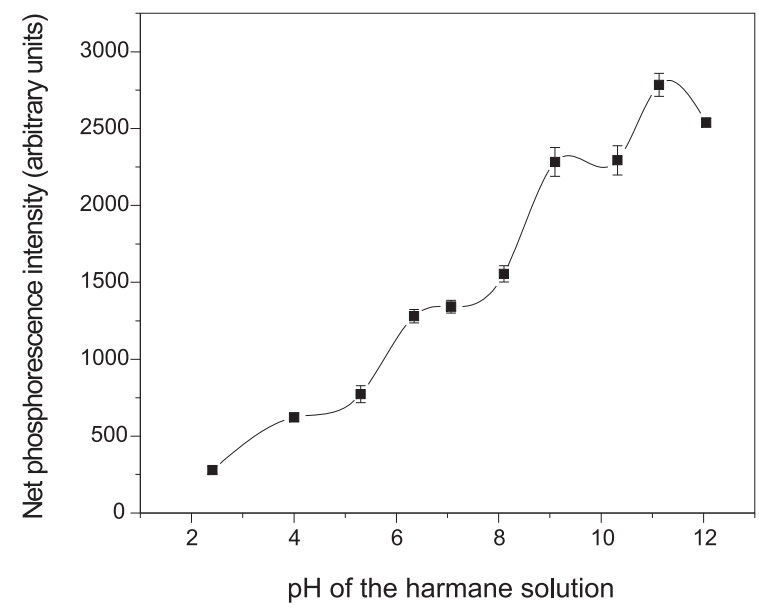

Figure 3. Influence of the $\mathrm{pH}$ of the harmane solution on its room-temperature phosphorescence in cellulose substrates in the presence of $\mathrm{AgNO}_{3}$
The concentrations of the heavy atom solutions deposited in the cellulose substrate were optimized. For $\mathrm{AgNO}_{3}$, solutions with lower concentrations deposited in the substrate enabled better results, as can be seen in Figure 4a. A decreasing of harmane signal was observed for higher amounts of $\mathrm{AgNO}_{3}$ due to a pre-filter effect caused by the formation of a dark film on the surface of the substrates spotted with silver solutions. For $\mathrm{AgNO}_{3}$, the $0.01 \mathrm{~mol} \mathrm{~L}^{-1}$ solution (5.4 $\mu \mathrm{g}$ of silver for $5 \mu \mathrm{L}$ solution volume) was selected for further experiments. In the case of $\mathrm{TINO}_{3}$, as the amount of $\mathrm{TINO}_{3}$ deposited in the cellulose substrate is increased, more intense RTP from harmane was obtained (Figure $4 \mathrm{~b}$ ). The $0.25 \mathrm{~mol} \mathrm{~L}^{-1} \mathrm{TINO}_{3}$ solution ( $255 \mu \mathrm{g}$ of thallium for $5 \mu \mathrm{L}$ solution volume) was then selected. Higher concentrations of $\mathrm{TlNO}_{3}$ were not tested because of limitations on the solubility of the salt and also because the single addition of solutions onto substrates was the chosen approach.
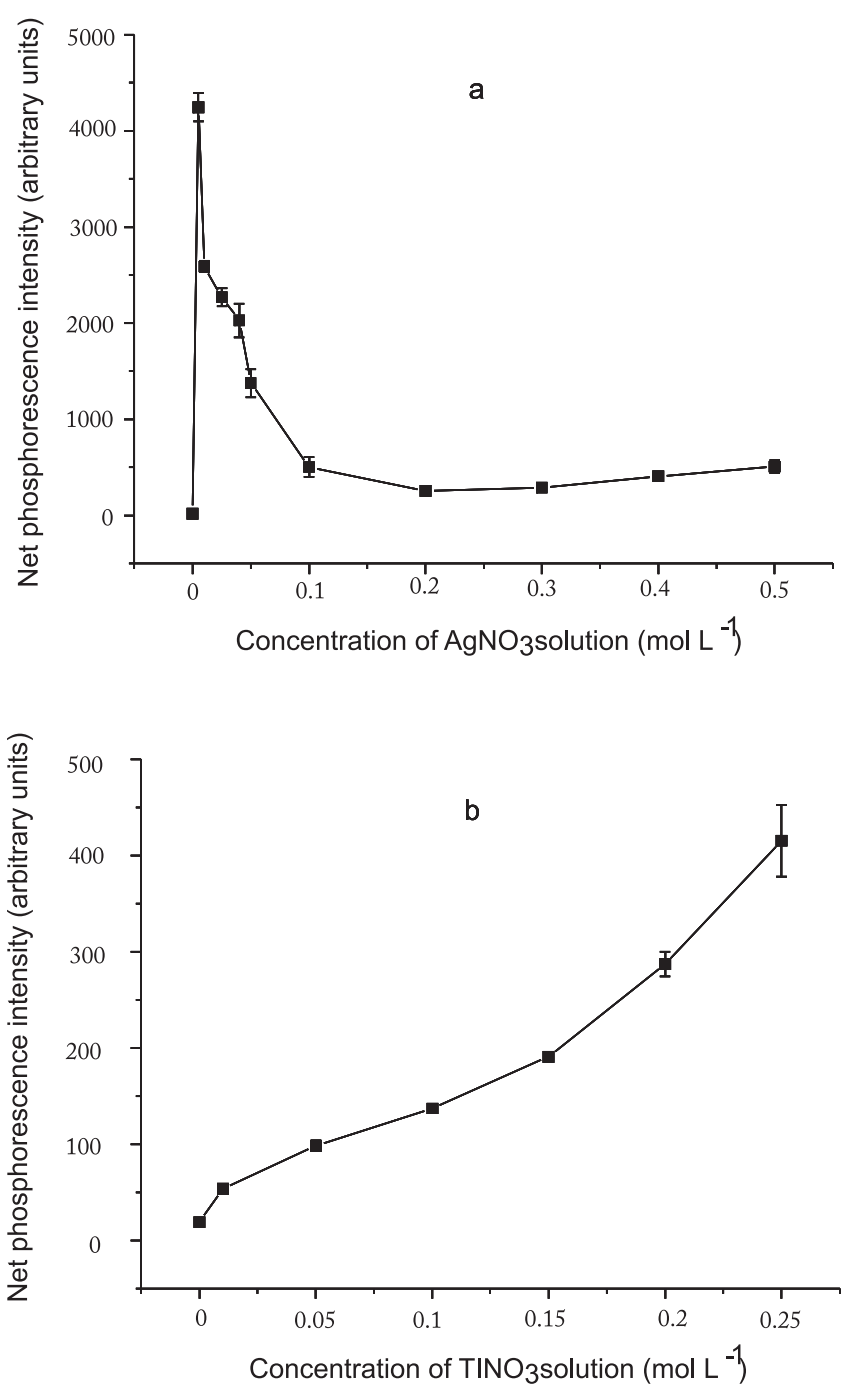

Figure 4. Phosphorescence of harmane in function of the concentration of the heavy atom enhancer solution spotted on the substrate: (a) $\mathrm{AgNO}_{3}$ and (b) $\mathrm{TlNO}_{3}$

Sodium dodecil sulfate (SDS) is known to improve the interaction between the analyte and the heavy atom with consequent enhancement of RTP intensity. The influence of increasing SDS quantities on the substrate was studied. For $\mathrm{AgNO}_{3}$, the use of SDS decreased the harmane RTP while no influence was observed in the case of $\mathrm{TINO}_{3}$. After dried on the surface of the substrate, SDS 
forms a supporting layer that may help to improve analyte rigidity and/or enable better contact between analyte and heavy atom. However, depending on the analyte, such improvements due to the presence of SDS are not observed ${ }^{18}$.

\section{Analytical figures of merit}

Analytical figures of merit were estimated using two different experimental conditions (Table 1), taken analytical curves for which each of the RTP intensities plotted was an average of four replicates. For RTP enhanced by $\mathrm{AgNO}_{3}$, a linear range (described by the following equation: $\mathrm{Y}=3.26 \times 10^{5} \mathrm{X}+79$, where the sensitivity of the curve is displayed in $\mathrm{ng}^{-1}$ and the linear coefficient is in arbitrary units of phosphorescence) was observed from the absolute limit of quantification $(0.39 \mathrm{ng})$ up to $456 \mathrm{ng}$ of harmane. The $\mathrm{r}^{2}$ value for this response was 0.9949. When $\mathrm{TlNO}_{3}$ was used as the phosphorescence enhancer, the linear response of the RTP signal extended from $8.1 \mathrm{ng}$ (absolute limit of quantification) to $911 \mathrm{ng}$ (Y $=3.73 \times 10^{4} \mathrm{X}+44, \mathrm{r}^{2}=0.9815$ ). For sample volumes of $5 \mu \mathrm{L}$, the absolute limits of detection of 0.12 and $2.4 \mathrm{ng}$ were obtained in the presence of $\mathrm{AgNO}_{3}$ and $\mathrm{TINO}_{3}$ respectively. Both, absolute limits of detection (ALOD) and absolute limit of quantification (ALOQ) were calculated using: $\mathrm{kS}_{\mathrm{b}} / \mathrm{m} \times 182.2 \mathrm{~g} \mathrm{~mol}^{-1} \times 5 \times 10^{-6} \mathrm{~L}$, where $\mathrm{S}_{\mathrm{b}}$ was the standard deviation of 16 blank measurements, $m$ is the sensitivity of the curve in $\mathrm{L} \mathrm{mol}^{-1}$ and $\mathrm{k}$ is the confidence value ( 3 for ALOD and 10 for ALOQ). Blank signals in the presence of $\mathrm{TINO}_{3}$ were about three times more intense than the blank signals observed in the presence of $\mathrm{AgNO}_{3}$. The standard deviations of these two different blanks were similar. Precision studies (repeatability) indicated a standard deviation of less than $3 \%$ for 10 successive measurements of $46 \mathrm{ng}$ of harmane ( $5 \mu \mathrm{L}$ of a solution $\left.1 \times 10^{-5} \mathrm{~mol} \mathrm{~L}^{-1}\right)$ placed in substrates containing either of the phosphorescence enhancers.

Table 1. Resume of the experimental and instrumental conditions optimized for the determination of harmane

\begin{tabular}{lcc}
\hline Parameter & \multicolumn{2}{c}{ Phosphorescence enhancer } \\
\hline & $\mathrm{AgNO}_{3}$ & $\mathrm{TlNO}_{3}$ \\
$\lambda_{\text {exc }} / \lambda_{\text {em }}$ & $250 / 455 \mathrm{~nm}$ & $254 / 493 \mathrm{~nm}$ \\
$\begin{array}{l}\text { Phosphorescence } \\
\text { concentration }\end{array}$ & $0.01 \mathrm{~mol} \mathrm{~L}{ }^{-1}$ & $0.25 \mathrm{~mol} \mathrm{~L}^{-1}$ \\
(effective mass) $^{\mathrm{a}}$ & $(5.4 \mu \mathrm{g})$ & $(255 \mu \mathrm{g})$ \\
Solvent system & Methanol/ & Methanol/buffer \\
& Britton-Robinson & \\
& buffer (pH 11) & \\
& $25 / 75 \%, \mathrm{v} / \mathrm{v}$ & $25 / 75 \%, \mathrm{v} / \mathrm{v}$ \\
\hline
\end{tabular}

${ }^{a}$ Effective mass of silver or thallium in the substrate considering $5 \mu \mathrm{L}$ of solution.

\section{Selectivity study}

The influence of four substances that could interfere in the determination of harmane was evaluated. Three of the chosen substances are naturally fluorescent and impose serious spectral interferences when fluorescence of harmane is measured without previous separation of components, for instance, by HPLC. The interferents were separated in two groups. The first one contain two substances (thalidomide and zidovudine) that could be used as a complementary or associated active substances in anti-HIV pharmaceutical preparations, since recent studies have indicated harmane as a potential drug for AIDS treatment ${ }^{7}$. Thalidomide presents natural fluorescence in a spectral range close to the one presented by harmane. Neither zidovudine nor thalidomide presented any phosphorescence signal under the experimental conditions optimized for harmane. Therefore, no spectral interferences are expected. In addition, by measuring RTP signals from harmane in mixtures containing either zidovudine or thalidomide in amounts up to ten times higher, no significant differences were found in comparison to the results observed from substrates containing only the equivalent amount of harmane. Such behavior indicated the absence of matrix interferences from these substances.

The second group of potential interferents included the indolic alkaloids reserpine and yohimbine that are therapeutically used as monoamine oxidase inhibitors having specific protective effect against seizure susceptibility. For the indolic alkaloids, when $\mathrm{TINO}_{3}$ was used as the phosphorescence enhancer, intense RTP is observed from yohimbine in the same spectral region of harmane ${ }^{23}$. Therefore, a spectral interference is expected. When $\mathrm{AgNO}_{3}$ was used as the phosphorescence enhancer, no RTP was observed for any of these two indolic alkaloids when spotted on the substrate from solutions at $\mathrm{pH}$ 11.0. Further studies indicated no decreasing of the harmane RTP signal when mixed in solution with each one of these indolic alkaloids in molar concentrations up to fifty times higher. Therefore, a selective determination of harmane in the presence of reserpine or yohimbine may be performed without previous separation of components.

\section{Determination of harmane in a simulated pharmaceutical tablet}

Since pharmaceutical formulations containing harmane were not available, the SSRTP method was tested by analyzing a laboratory simulated tablet. This tablet was prepared as an association of harmane and thalidomide. This was made by pulverizing separately three commercial tablets (Talidomida $\mathrm{CEME}^{\circledR}$ ) containing an equivalent amount of $100 \mathrm{mg}$ of thalidomide and mixing to each of the resultant powder to $60 \mathrm{mg}$ of harmane. These three portions of powder were treated with methanol to dissolve the analyte, and the resultant solutions were gently filtered under vacuum. Aliquots of these solutions were collected and diluted in methanol/Britton-Robinson buffer ( $\mathrm{pH} 11.0$ ) 25/75\% v/v to be quantified using the analytical curve procedure and substrates containing $\mathrm{AgNO}_{3}$ as phosphorescence enhancer. The same quantification procedure was made using substrates containing $\mathrm{TINO}_{3}$, however, in this case, the sample was diluted in methanol/ water $25 / 75 \% \mathrm{v} / \mathrm{v}$ previously to the deposition on the substrate. A mean recovery of $104 \pm 6 \%(n=6$, three for each heavy atom salt), was achieved, indicating the suitability of such application. These same laboratory simulated tablets were analyzed by micellar electrokinetic chromatography (MEKC) in order to compare to the recoveries achieved using SSRTP. The mean recovery of $96 \pm 6 \%$ $(n=5)$ was obtained using MEKC. A statistical test indicated no difference in the results achieved by the two methods $(\mathrm{p}=0.05$; $\mathrm{n}_{\text {SSRTP }}=6 ; \mathrm{n}_{\text {MEKC }}=5$ ). Figure 5 shows TINO $_{3}$ enhanced RTP spectrum and electropherogram for thalidomide based formulation in the presence and in the absence of harmane.

\section{CONCLUSIONS}

Room temperature phosphorescence of harmane is reported for the first time and a SSRTP method for its determination was developed. Intense RTP was achieved in cellulose substrates containing either $\mathrm{AgNO}_{3}$ or $\mathrm{TINO}_{3}$ as phosphorescence enhancers. Optimized experimental and instrumental conditions allowed 

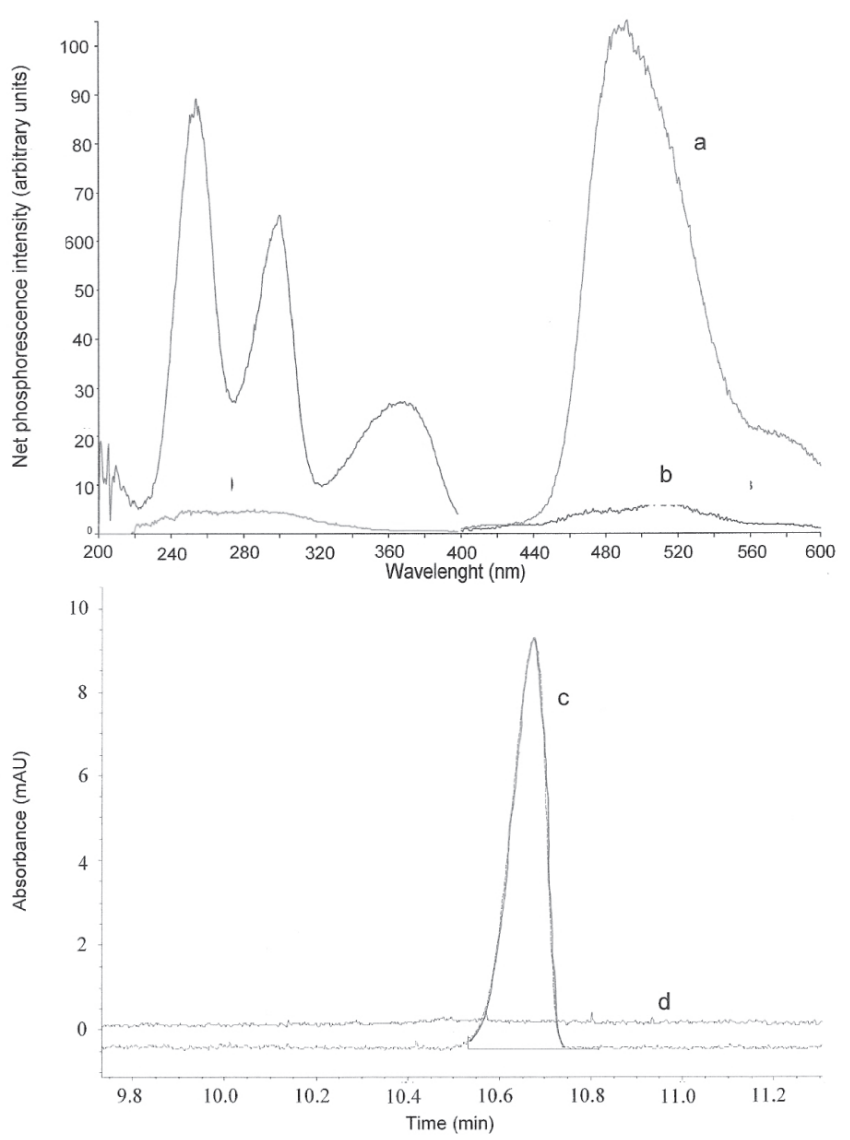

Figure 5. (A) $\mathrm{TlNO}_{3}$ enhanced room-temperature phosphorescence spectrum for a mixture of harmane and thalidomide (a) and for thalidomide (b); $(B)$ $M E C K$ electropherogram for a mixture of harmane and thalidomide (c) and for thalidomide $(d)$

excellent sensitivity and satisfactory dynamic linear range to be achieved. Interference studies were made and the experimental results indicated a selective capability of the method towards several concomitant substances (two indolic alkaloids, thalidomide and zidovudine). A simulated harmane tablet, containing thalidomide as a concomitant drug, was successfully analyzed by the method. When compared to the results achieved using MECK, it has been demonstrated that SSRTP can be potentially used for such analytical application. SSRTP method is simple and selective, eliminating the need for neither powerful separation methods (HPLC ${ }^{20}$, for instance) to isolate the analyte from the tested potentially interferent substances nor multivariate approaches ${ }^{24}$ for the determination of harmane in mixtures.

\section{ACKNKOWLEDGEMENTS}

The authors thank FAPERJ-Brazil (grants E-26/150.700/2003 and E-26/170.318/2002) and FINEP, Brazil for supporting this research. The authors also thank CNPq-Brazil for scholarships.

\section{REFERENCES}

1. Hecimovic, H.; Goldstein, J. D.; Sheline, Y. I.; Gillian, F. G.; Epilepsy \& Behaviour 2003, 4, 825.

2. Aricioglu, F.; Yillar, O.; Korcegez, E.; Berkman, K.; Ann. N. Y. Acad. Sci. 2003, 1009, 190.

3. Aassila, H.; Bourguet-Kondracki, M. L.; Rifai, S.; Fassouane, A.; Guyot, M.; Mar. Biotechnol. 2003, 5, 163.

4. Coddling, P. W.; Can. J. Chem. 1983, 61, 529.

5. Evans, A. T.; Croft, S. L.; Phytother. Res. 1987, 1, 25.

6. Di Giorgio, C.; Delmas, F.; Ollivier, E.; Elias, R.; Balansard, G.; TimonDavid, P.; Exp. Parasitol. 2004, 106, 67.

7. Ishida, J.; Wang, H. K.; Masayoshi, O.; Cosentino, C. L.; Hu, C. Q.; Lee, K. H.; J. Nat. Prod. 2000, 64, 958.

8. Groger, D.; Plant Med. 1959, 7, 461.

9. Adachi, J.; Mizoi, Y.; Naito, T.; Yamamoto, K.; Fujiwara, S.; Nimomiya, I.; J. Chromatogr. 1991, 538, 331.

10. Poindexter, E. H.; Carpenter, R. D.; Phytochemistry 1962, 1, 215.

11. Nishigata, H.; Yoshida, D.; Matsumoto, T.; Agric. Biol. Chem. 1980, 44, 209

12. Bidder, T. G.; Schomaker, D. W.; Boetger, H. S.; Evans, H. E.; Cummins, J. T.; Life Sci. 1979, 25, 157.

13. Pfau, W.; Skog, K.; J. Chromatogr., B: Anal. Technol. Biomed. Life Sci. 2004, 802, 115 .

14. Olba, A.; Tomas, F.; Zabala, I.; Medina, P.; J. Photochem. 1987, 39, 263.

15. Varela, A. P.; Burrows, H. D.; Douglas, P.; Miguel, M. G.; J. Photochem. Photobiol. 2001, 146, 29.

16. Marques, A. D. S.; Souza, H. F.; Costa, I. C.; Azevedo, W. M.; J. Mol. Struct. 2000, 520, 179.

17. Vo Dinh, T.; Room temperature phosphorimetry for chemical analysis, Chemical analysis series vol. 101, Jonh Wiley \& Sons: New York, 1994, p. 243-250.

18. Aucelio, R. Q.; Campíglia, A. D.; Talanta 1994, 41, 2131.

19. Miller, J. N.; Trends Anal. Chem. 1981, 1, 33.

20. Cavin, J. C.; Rodriguez, E.; J. Chromatogr. 1988, 447, 432.

21. Zheng, W.; Wang, S.; Barnes, L. F.; Guan,Y.; Louis E. D.; Anal. Biochem. 2000, 279, 125

22. Cheng, J.; Mitchelson, K. R.; J. Cromatogr., A 1997, 761, 297.

23. Aucelio, R. Q.; Arruda, A. F.; Anal. Sci. 2002, 18, 831.

24. Hemmateenejad, B.; Abbaspour, A.; Maghami, H.; Miri, R.; Panjehshahin, M. R.; Anal. Chim. Acta 2006, 575, 290. 